Plant Tissue Cult. \& Biotech. 31(2): 135-142, 2021 (December)

DOI: https://doi.org/10.3329/ptcb.v31i2.57341

(C)Bangladesh Assoc. for Plant Tissue Culture \& Biotechnology
ISSN 1817-3721, E-ISSN 1818-8745

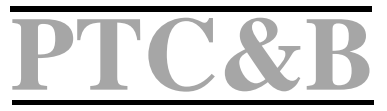

\title{
Indigenous Lipase Producing Bacteria for Lipid-rich Wastewater Treatment
}

\author{
Lovely Aktar, Mohammad Moniruzzaman', Yasuzo Sakai² \\ and Mihir Lal Saha* \\ Department of Botany, University of Dhaka, Dhaka-1000, Bangladesh \\ Keywords: Bacteria, Consortium, Lipase, Monoculture, Organic matter
}

\begin{abstract}
This study was undertaken to evaluate the removal of lipid-rich organic matter from wastewater by lipase producing bacteria. Ten potential lipase producing bacteria were isolated from lipid-rich environments in and around Dhaka Metropolitan city. Three of them produced lipase higher than $10 \mathrm{U} / \mathrm{ml}$. These three isolates and their consortium were used for synthetic wastewater treatment in the laboratory. The initial COD value of synthetic wastewater was 1,200 $\mathrm{mg} /$. COD removal efficiencies in the synthetic wastewater were $74.75,73.33$ and $66.67 \%$ by the Stenotrophomonas maltophilia e-a22, Pseudomonas aeruginosa 12 and Bacillus subtilis 20B, respectively. Stenotrophomonas maltophilia showed better COD removal performance $(74.75 \%)$ in case of monoculture. But consortium showed better COD removal (83.33\%) than that of monoculture. Therefore, it could be concluded that consortium of three isolates will be more useful for wastewater treatment as seed cultures in the wastewater treatment plant associated with the lipid-rich wastewater.
\end{abstract}

\section{Introduction}

Lipid, characterized by fats, oils and greases (FOG) and long chain fatty acids (LCFA) are major organic components of wastewater (Chipasa and Medrzycka 2006). Lipid in wastewater often cause major problems in natural systems of biological wastewater treatment processes because of oil film on water surface, preventing oxygen diffusion from air into water and leading to the death of many forms of aquatic flora and fauna (Cammarota and Freire 2009). Aggregates formed by the oil droplets and other particles present in wastewater could also block water drainage systems and with high chemical oxygen demand (COD) in wastewater (Mendes et al. 2010).

\footnotetext{
*Author for correspondence: <sahaml@yahoo.com>. ${ }^{1}$ Bangladesh Council of Scientific and Industrial Research (BCSIR), Dr. Qudrat-I-Khuda Road, Dhanmondi, Dhaka-1205, Bangladesh. ${ }^{2}$ Graduate School of Engineering, Utsunomiya University, Japan.
} 
Treatment of wastewater is essential to prevent the contamination of surface water as well as drinking water and the entry of contaminants into the food chain. Treating lipid based wastewater sources is very broad, as the oil in the oil industry, oil refining, oil storage, transportation and petrochemical industries in the production process generate lot of oily wastewater(Chen and He 2003, Machin-Ramirez et al. 2008). Therefore, oily wastewater treatment is urgently needed to address the challenges of environmental pollution. These challenges might be ecofriendly solved by the bacteria which are already adapted with the contaminated sites.

The biological process is the main treatment system in wastewater plant. In biological methods, bacteria with high lipase activities can degrade oil. The most common method of treating lipid-rich wastewater is enhancing lipase producers either in monoculture or mixed culture. Different industries generate strong wastewaters characterized with high BOD and COD, and lipid source could increase BOD level. These types of effluents can be treated by cultivating lipase producing bacteria (Nelson and Rawson 2010). Generally Pseudomonas, Bacillus and Acinetobacter are used in the wastewater treatment plant (Mongkolthanaruk and Dharmsthiti 2002).

Considering the importance and applications of biotechnologically and industrially valuable bacterial enzymes, the present study was aimed to screen indigenous lipase producing bacteria isolated from lipid-rich environment for wastewater treatment.

\section{Materials and Methods}

The soil and water samples were collected from different lipid-rich environmental areas located in and around Dhaka Metropolitan city, Bangladesh (Aktar et al. 2016). They were subjected to serial dilutions. Actively growing bacterial colonies were randomly selected from dilution plates and grown on two lipid based media-Tributyrin Agar (TBA) and Tween Agar (TA) for $72 \mathrm{hrs}$ at $37^{\circ} \mathrm{C}$ for detection of lipolytic activity (Kumar et al. 2012). The lipolytic activities of all isolates were compared by measuring the width of the areas of clearing expressed as zone ratio in TBA medium. Zone ratio was determined by calculating zone diameter $(\mathrm{mm})$ divided by colony diameter $(\mathrm{mm})$ (Bueno et al. 2014). Potential ten isolates were identified using $16 \mathrm{~S}$ rRNA sequence based on molecular technique (Aktar et al. 2016).

For lipase production, the liquid culture medium, Tryptone Soya Broth (TSB) with $1 \%$ olive oil substrate was used (Anbu et al. 2011). An Erlenmeyer flask (250 ml) containing $100 \mathrm{ml}$ of TSB medium was inoculated with $1 \%$ of the pre culture $(0.5$ McFarland standards) prepared in Nutrient Broth (NB). The inoculated flasks were incubated for $96 \mathrm{hrs}$ at $37^{\circ} \mathrm{C}$ at $150 \mathrm{rpm}$ on a shaking incubator (DAIHAN-LABTECH). Samples were removed aseptically at an interval of $24 \mathrm{hrs}$ and cell free supernatant was recovered by centrifugation at $9,000 \mathrm{rpm}$ for $20 \mathrm{~min}$ at $4^{\circ} \mathrm{C}$ (Sagar et al. 2013). The clear supernatant was collected as source of crude enzyme for determination of lipolytic activity. 
Standard method was followed for the estimation of lipase activity of the bacterial isolates (Marseno et al. 1998). Lipase activity was estimated in a screw cap vial containing $2 \mathrm{ml}$ of reaction mixture containing $60 \%(\mathrm{v} / \mathrm{N})$ olive oil in iso-octane. The $60 \%(\mathrm{v} / \mathrm{v})$ olive oil in iso-octane was prepared by mixing $60 \mathrm{ml}$ of olive oil with $40 \mathrm{ml}$ of iso-octane. The reaction was started by adding of $20 \mu \mathrm{l}$ of crude enzyme solution at $30^{\circ} \mathrm{C}$ at $150 \mathrm{rpm}$ for 30 $\mathrm{min}$. Then the reaction was stopped by placing the reaction mixture in an ice bath for 10 min. About $200 \mu \mathrm{l}$ of the aliquots was added to the mixture containing $1800 \mu \mathrm{l}$ of isooctane and $400 \mu \mathrm{l}$ of cupric acetate pyridine at $\mathrm{pH}$ 6.0. The upper layer (iso-octane fraction) was pipetted and the amount of free fatty acid that dissolved in iso-octane layer was determined spectrophotometrically by measuring the optical density at $715 \mathrm{~nm}$. Lipase activity was estimated by quantification of oleic acid released as free fatty acid from olive oil by bacterial lipase which is determined following oleic acid standard curve. Released oleic acid was estimated up to $96 \mathrm{~h}$ and results were recorded every 24 hrs intervals. One unit of lipase activity was defined as the amount of enzyme that produced one $\mu$ mole fatty acid per min.

A synthetic wastewater containing the following compositions was prepared as described by Chen et al. (2009): ( $\mathrm{g} \Lambda$ ) glucose (7.5), $\mathrm{NH}_{4} \mathrm{Cl}(1.5), \mathrm{K}_{2} \mathrm{HPO}_{4}(0.2), \mathrm{KH}_{2} \mathrm{PO}_{4}$ $(0.2), \mathrm{MgSO}_{4} .7 \mathrm{H}_{2} \mathrm{O}(0.25), \mathrm{CaCl}_{2} .2 \mathrm{H}_{2} \mathrm{O}(0.3)$. Trace element solution $(0.5 \mathrm{ml})$ was added for this medium with the following compositions (mg/L): $\mathrm{H}_{3} \mathrm{BO}_{3}(50), \mathrm{ZnCl}_{2}(50), \mathrm{CuCl}_{2}(30)$, $\mathrm{MnSO}_{4} \cdot \mathrm{H}_{2} \mathrm{O}(500), \mathrm{CoCl}_{2} \cdot \mathrm{H}_{2} \mathrm{O}(50),\left(\mathrm{NH}_{4}\right)_{6} \mathrm{MoO} .24 \mathrm{H}_{2} \mathrm{O}(50)$. The solution was diluted to 100 times $(1 \mathrm{ml}$ stock $+99 \mathrm{ml}$ distilled water). One percent olive oil was added in the diluted medium. The $\mathrm{pH}$ was adjusted to 7.0 and the media was autoclaved at $121^{\circ} \mathrm{C}$ for 15 minutes. In the laboratory synthetic wastewater treatment was carried out by two different ways. Firstly, the wastewater treatment was done by monoculture. Secondly, by consortium or mix culture of bacterial isolates. Seed culture was prepared in NB medium. Inoculated Erlenmeyer flasks $(250 \mathrm{ml})$ containing $100 \mathrm{ml}$ synthetic wastewater with $5 \%(\mathrm{v} /)$ seed culture at OD value with $600 \mathrm{~nm}=1$ were then incubated in a shaking incubator at $37^{\circ} \mathrm{C}$ at $150 \mathrm{rpm}$ for $96 \mathrm{hrs}$. COD analysis was done periodically at $24 \mathrm{hrs}$ intervals.

Statistical analysis was performed with the Statistical Package for the Social Sciences (SPSS) v.20.0 for windows (SPSS, SAS Institute Inc. Cary, USA). The data were analyzed to determine the descriptive statistics such as Mean and Standard deviation (SD). Evaluation on differences between groups was based on the oneway ANOVA test at $95 \%$ confidence interval with Duncan's Multiple Range Test. Value of $p<0.05$ was regarded as statistically significant.

\section{Results and Discussion}

For analysis of the degree of lipolysis, zone ratio of 10 selected isolates was calculated from TBA plates and is shown in Table 1. Among the isolates, the highest zone ratio showed by the isolate $\mathrm{S}_{4} \mathrm{P}-4$ and the measured zone ratio was $4.08 \pm 0.47$.The formation of 
clear zone due to hydrolysis of tributyrin on TBA medium is shown in Fig. 1. The formation of opaque zone around the inoculated bacterial colony on TA medium after $72 \mathrm{~h}$ of incubation is shown in Fig. 2.

Table 1. Lipolytic activity as measured by zone ratio (mean \pm SD) on TBA plate $(n=3)$.

\begin{tabular}{llccc}
\hline Strain & \multicolumn{1}{c}{ Isolates } & $\begin{array}{c}\text { Zone diameter } \\
(\mathrm{mm})\end{array}$ & $\begin{array}{c}\text { Colony diameter } \\
(\mathrm{mm})\end{array}$ & Zone ratio \\
\hline $\mathrm{S}_{3} \mathrm{~T}-5$ & Bacillus sp. BTMASC2 & $22.83 \pm 1.53$ & $9.67 \pm 0.58$ & $2.36 \pm 0.10$ \\
$\mathrm{~S}_{3} \mathrm{~T}-9$ & B. subtilis 20B & $25.00 \pm 4.09$ & $9.50 \pm 2.18$ & $2.63 \pm 0.46$ \\
$\mathrm{~S}_{4} \mathrm{P}-4$ & B. subtilis HRBS-10TDI13 & $24.50 \pm 0.87$ & $6.00 \pm 0.50$ & $4.08 \pm 0.47$ \\
$\mathrm{~S}_{10} \mathrm{P}-2$ & B. subtilis CI1 & $29.83 \pm 2.75$ & $15.33 \pm 1.15$ & $1.95 \pm 0.15$ \\
$\mathrm{~S}_{3} \mathrm{P}-1$ & B. pumilusJa02 & $19.50 \pm 4.77$ & $7.00 \pm 0.50$ & $2.79 \pm 0.62$ \\
$\mathrm{~S}_{7} \mathrm{~N}-1$ & Staphylococcus epidermidis 6E02 & $16.83 \pm 4.48$ & $5.67 \pm 0.76$ & $2.97 \pm 0.90$ \\
$\mathrm{~S}_{1} \mathrm{~N}-2$ & Stenotrophomonas maltophilia $\mathrm{e}-\mathrm{a} 22$ & $17.17 \pm 1.89$ & $7.83 \pm 0.29$ & $2.19 \pm 0.28$ \\
$\mathrm{~S}_{1} \mathrm{~N}-7$ & Serratia rubidaea 9B & $23.17 \pm 1.89$ & $6.33 \pm 0.58$ & $3.66 \pm 0.29$ \\
$\mathrm{~S}_{10} \mathrm{P}-1$ & Pseudomonas aeruginosa 12 & $23.50 \pm 3.00$ & $14.69 \pm 1.76$ & $1.60 \pm 0.13$ \\
$\mathrm{~S}_{10} \mathrm{~T}-8$ & Acinetobacter johnsonii 372 & $21.50 \pm 1.76$ & $8.33 \pm 0.76$ & $2.58 \pm 0.24$ \\
\hline
\end{tabular}
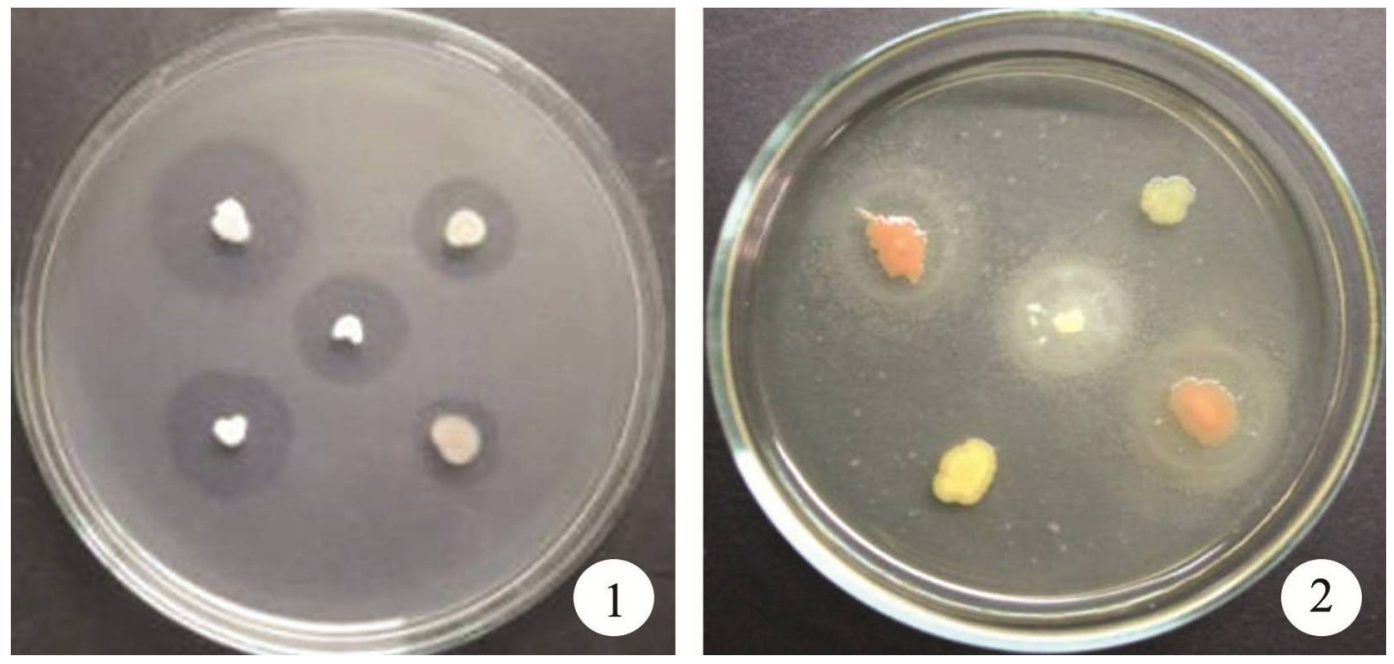

Figs 1-2: 1. Photograph showing growth and clear zone on TBA medium. 2. Photograph showing growth and opaque zone on TA medium.

For lipase production, six Gram positive and four Gram negative bacterial isolates were selected. Lipase production of Gram positive bacterial isolates is shown in Fig. 3. The lipase producing capabilities of Gram positive isolates ranged from $0.89 \pm 0.63$ to 13.50 
$\pm 0.14 \mathrm{U} / \mathrm{ml}$. Lipase production of Gram negative bacterial isolates is shown in Fig. 4. In case of Gram negative isolates lipase production was in between $1.28 \pm 0.25$ and $26.89 \pm$ $2.68 \mathrm{U} / \mathrm{ml}$. Among the bacterial isolates, the Gram negative Stenotrophomonas maltophilia e-a22 was found to be the most potent isolate for lipase production which could produce lipase up to $26.89 \pm 2.68 \mathrm{U} / \mathrm{ml}$ at $72 \mathrm{hrs}$ of incubation. Pseudomonas aeruginosa 12 could produce lipase up to $10.89 \pm 0.30 \mathrm{U} / \mathrm{ml}$ at $24 \mathrm{~h}$ of incubation. Padhiar and Kommu (2016) reported almost similar type of observation by Pseudomonas aeruginosa with lipase production $8.32 \mathrm{U} / \mathrm{ml}$. Another isolate Bacillus subtilis 20B could produce lipase up to $13.50 \pm 0.14 \mathrm{U} / \mathrm{ml}$ at $24 \mathrm{hrs}$ of incubation. Musa and Tayo (2012) found lipase production of Bacillus sp. as $3.8 \mathrm{U} / \mathrm{ml}$. In another research, Bacillus subtilis isolated from oilcontaminated wastewater could produce lipase $9.33 \mathrm{U} / \mathrm{ml}$ (Iqbal and Rehman 2015). These three isolates were selected for wastewater treatment.

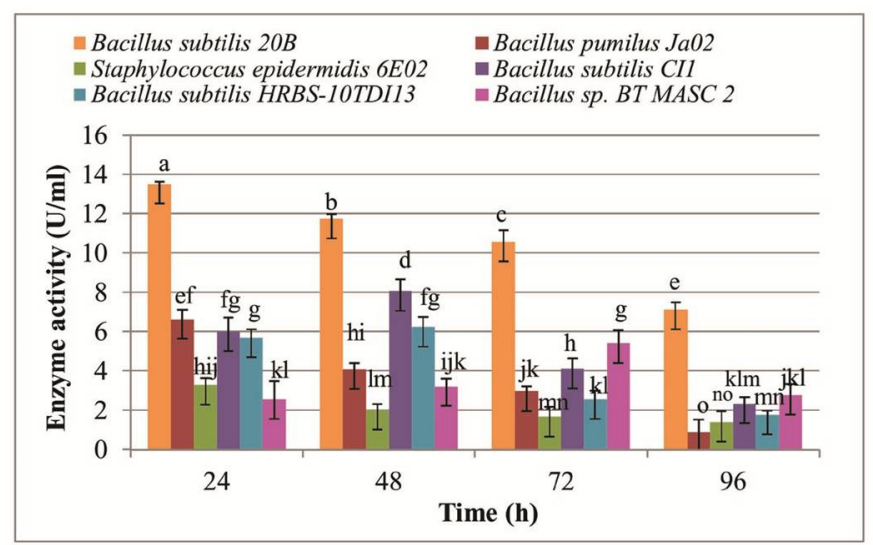

Fig. 3. Lipase production of 6 Gram positive bacterial isolates. Error bar representing the experimental error of Sd. Means with different letters designations within the column are significantly different at $p<0.05$ by $\operatorname{DMRT}(\mathrm{n}=3)$.

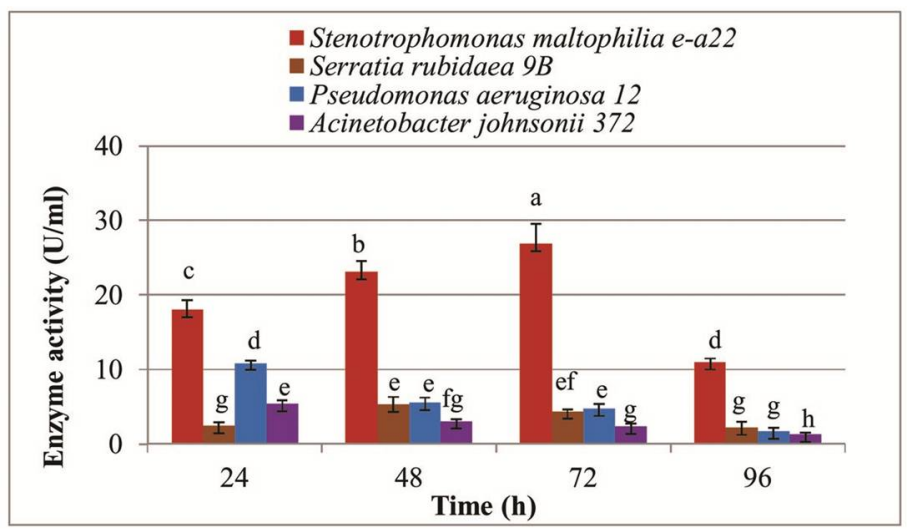

Fig. 4. Lipase production of 4 Gram negative bacterial isolates. Error bar representing the experimental error of $\mathrm{Sd}$. Means with different letters designations within the column are significantly different at $\mathrm{p}<0.05$ by DMRT $(\mathrm{n}=3)$. 
Wastewater treatment in terms of COD was carried out in the laboratory. The initial COD concentration of synthetic wastewater was $1,200 \mathrm{mg} /$. COD measurement was carried out at $96 \mathrm{~h}$ of treatment under aerobic condition. The COD value of wastewater reduced from 1,200 $\mathrm{mg} \mathrm{L}$ to 303,320 and $400 \mathrm{mg} \mathrm{L}$ after $96 \mathrm{~h}$ of treatment by the individual isolates of Stenotrophomonas maltophilia e-a22, Pseudomonas aeruginosa 12 and Bacillus subtilis 20B, respectively. The strain Stenotrophomonas maltophilia e-a22 was found to be the best with COD removal rate of $74.75 \%$ followed by Pseudomonas aeruginosa 12 (73.33\%) and Bacillus subtilis 20B (66.67\%).

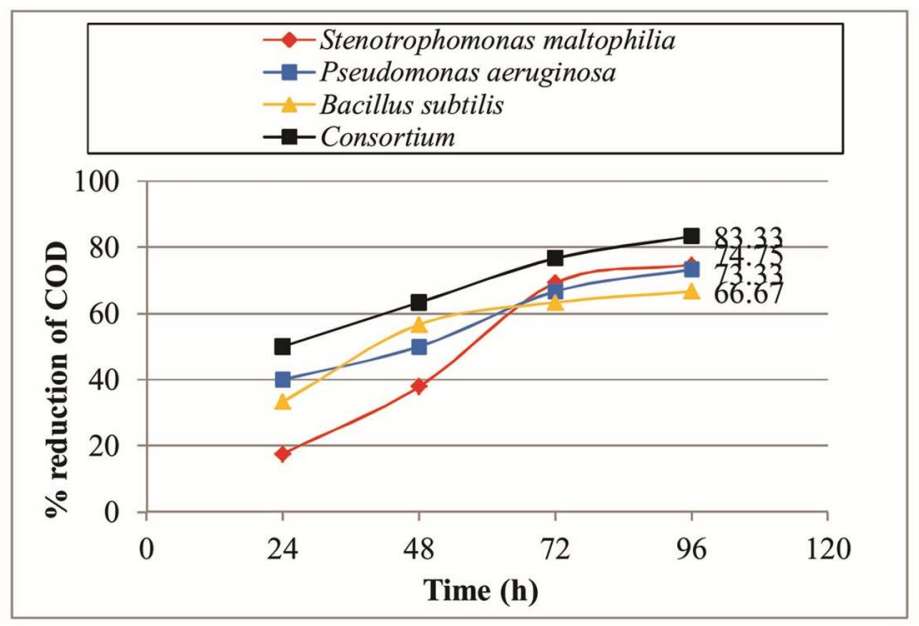

Fig. 5. Wastewater treatment using monoculture and consortium.

Consortium of Stenotrophomonas maltophilia e-a22, Pseudomonas aeruginosa 12 and Bacillus subtilis 20B was found to be better than that of monoculture. There was a considerable decrease in COD $(200 \mathrm{mg} \Lambda)$ on the 4 th day of the treatment. The consortium attained maximum COD removal up to $83.33 \%$ (Fig. 5). Since consortium gave better result due to their synergistic effect and could reduce COD efficiently from synthetic wastewater. Like present study similar work had been carried out with other lipaseproducing strain Pseudomonas aeruginosa SL-72 (Verma et al. 2012). The crude lipase of Pseudomonas aeruginosa SL-72 was added to wastewater contaminated with crude oil, resulting $86.39 \%$ reduction of COD after 7 days of treatment. Orapin and and Kriangkrai (2010) reported that single culture of Pseudomonas sp. was highly efficient and showed COD removal of $95.81 \%$ within 8 days of treatment. Serikovna et al. (2013) reported FOG removal by Pseudomonas aeruginosa G23 with the degradation rate of $62-66 \%$. Hu et al. (2018) had found that Pseudomonas sp. was very effective in removing organic matter from industrial wastewater. Three bacterial isolates, Stenotrophomonas maltophilia e-a22, Pseudomonas aeruginosa 12 and Bacillus subtilis 20B could be used as seeding inocula to treat oily wastewater. 


\section{Acknowledgements}

The authors would like to express their thanks to the department of Botany, University of Dhaka, for providing research facility. The authors are sincerely grateful to the Ministry of National Science and Technology (NST) for financial support. The authors also grateful to Bangladesh Council of Scientific and Industrial Research (BCSIR) for supporting to determine COD. The corresponding author is very much grateful to his foreign collaborator for helping to get insight research idea and suggestion during this research program.

\section{References}

Anbu P, Noh MJ, Kim DH, Seo JS, Hur BK and Min KH (2011) Screening and optimization of extracellular lipases by Acinetobacter species isolated from oil-contaminated soil in South Korea. African J. Biotechnol. 10(20): 4147-4156.

Aktar L, Khan FI, Islam T, Mitra S and Saha ml (2016) Isolation and characterization of indigenous lipase producing bacteria from lipid-rich environment. Plant Tissue Cult. and Biotechnol. 26(2):243-253.

Bueno PRM, Oliveira TF, Caliari M, Castiglioni GL and Junior SS (2014) Selection and optimization of extracellular lipase production using agro-industrial waste. African J.Biotechnol. 13(4): 566-573.

Cammarota MC andFreire DMG (2009) Performance and molecular evaluation of ananaerobic system with suspended biomass for treating wastewater with high fat content after enzymatic hydrolysis. Bioresour. Technol. 100(24): 6170-6176.

Chen G and He G (2003) Separation of water and oil from water-in-oil emulsion by freezethaw method. Purif. Technol. 31(1): 83-89.

Chen Y, Lin JL, Jones G, Fu S and Zhan H (2009) Enhancing biodegradation of wastewater by microbial with fractional factorial design. J. Hazard. Mater. 171(1): 948-953.

Chipasa KB and Medrzycka K (2006) Behavior of lipids in biological wastewater treatment processes. J. Ind. Microbiol. Biotechnol. 33(8): 635-645.

Hu J, Cai W, Wang C, Du X, Lin J and Cai J (2018) Purification and characterization of alkaline lipase production by Pseudomonas aeruginosa HFE733 and application for biodegradation in food wastewater treatment. Biotechnol. Biotechnol. equip. 32(3): 583-590.

Iqbal SA and Rehman A (2015) Characterization of lipase from Bacillus subtilis I-4 and its potential use in oil contaminated wastewater. Brazilian Arch. Biol. Technol. 58(5): 789-797.

Kumar A, Parihar SS and Batra N (2012). Enrichment, isolation and optimization of lipaseproducing Staphylococcus sp. from oil mill waste (Oil cake). J. Exp. Sci. 3(8): 26-30.

Machin-Ramirez C, Okohc AI, Morales D, Mayolo-Deloisa K, Quintero R and Trejo-Hernandez MR (2008) Slurry-phase biodegradation of weathered oily sludge waste. Chemosphere 70(4): 737-744.

Marseno DW, Indrati R and Ohta Y (1998) A simplified method for determination of free fatty acids for soluble and immobilized lipase assay. Indonesian food Nutri. progress 5(2): 79-83. 
Mendes AA, Pereira EB, Furigo AJ and Castro HF (2010) Anaerobic biodegradability of dairy wastewater pretreated with porcine pancreas lipase. Brazilian Arch. Biol. Technol. 53(6): 12791284.

Mongkolthanaruk W and Dharmsthiti S (2002) Biodegradation of lipid-rich wastewater by a mixed bacterial consortium. Int. Biodeter. Biodegrad. 50(2): 101-105.

Musa H and Tayo BCA (2012) Screening of microorganisms isolated from different environmental samples for extracellular lipase production. Australian J. Technol. 15(3): 179-186.

Nelson DJ and Rawson R (2010) Method of growing bacteria for use in wastewater treatment. United States Patent 7658851, www.freepatentsonline.com.

Orapinand B and Kriangkrai P (2010) Lipase producing microorganism for use in contaminated fat and oil kitchen wastewater treatment. Water Res. 30(3): 167-171.

Padhiar AR andKommu S (2016) Isolation, characterization and optimization of bacteria producing amylase. Int. J. Adv. Res. Biol. Sci. 3(7): 1-7.

Sagar K, Bashir Y, Phukan MM and Kamwar BK (2013) Isolation of lipolytic bacteria from waste contaminated soil: a study with regard to process optimization for lipase. Int. J. Sci. Technol. Res. 2(10): 214-218.

Serikovna SZ, Serikovich KS, Sakenovna AS, Murzakhmetovich SS and Khamitovich AK (2013) Screening of lipid degrading microorganisms for wastewater treatment. Malaysian J. Microbiol .9(3): 219-226.

Verma S, Saxena Jand Prasanna R (2012) Medium optimization for a novel crude-oil degrading lipase from Pseudomonas aeruginosa SL72 using statistical approaches for bioremediation of crude-oil. Biocatal. Agri. Biotechnol. 1(4): 321-329. 